\title{
Comparative study of the antioxidant and immunomodulant activities between yeast and lab fermented papaya
}

\author{
Cristiana Caliceti ${ }^{1}$, Francesca Fortini' ${ }^{2}$, Giorgio Aquila ${ }^{2}$, Eleonora Pagnotta ${ }^{3}$, Luisa \\ Ugolini $^{3}$, Patrizia Simoni ${ }^{4}$, Donato Calabria ${ }^{1}$, Manuela Rizzoli ${ }^{7}$, Federica Guidi ${ }^{7}$, Roberto \\ Ferrari $^{6}$, Aldo Roda ${ }^{1}$ and Paola Rizzo ${ }^{5}$
}

${ }^{1}$ Department of Chemistry "Giacomo Ciamician" and Centro Interdipartimentale di Ricerca Industriale Energia e Ambiente (CIRI EA) - Alma Mater Studiorum, University of Bologna, Bologna, Italy; Istituto Nazionale Biostrutture e Biosistemi (INBB), Roma, Italy; ${ }^{2}$ Department of Medical Sciences, University of Ferrara, Ferrara, Italy; ${ }^{3}$ Council for Agricultural Research and Economics - Research Centre for Cereal and Industrial Crops, Bologna, Italy; ${ }^{4}$ Department of Medical and Surgical Science - DIMEC, University of Bologna, S.Orsola-Malpighi Hospital, Bologna, Italy; ${ }^{5}$ Department of Morphology, Surgery and Experimental Medicine, University of Ferrara, Ferrara, Italy; Maria Cecilia Hospital, GVM Care\&Research, E.S: Health Science Foundation, Cotignola, Italy; ${ }^{6}$ Cardiovascular Institute and Laboratory for Technologies of Advanced Therapies (LTTA), University of Ferrara, Ferrara, Italy; Maria Cecilia Hospital, GVM Care\&Research, E.S: Health Science Foundation, Cotignola, Italy; ${ }^{7}$ Incos Cosmeceutica Industriale, Funo di Argelato, Bologna Italy

Submission Date: September $20^{\text {th }}$, 2017, Acceptance Date: January $27^{\text {th }}$, 2017, Publication Date: January $31^{\text {st }}, 2018$

Citation: Caliceti C., Fortini F., Aquila G., Pagnotta E., Ugolini L., Simoni P., Calabria D., Rizzoli M., Guidi F., Ferrari R., Roda A., Rizzo P., Comparative study of the antioxidant and immunomodulant activities between yeast and lab fermented papaya. Functional Foods in Health and Disease 2017; 8(1): 49-61. DOI: https://doi.org/10.31989/ffhd.v8i1.395

Corresponding author: Cristiana Caliceti, PhD, Department of Chemistry "Giacomo Ciamician," Alma Mater Studiorum, University of Bologna, Bologna, Italy

\begin{abstract}
Background: Dietary supplements of Carica papaya Linn fermented with yeast using a biotechnological process have well recognized positive effects on immunological, hematological, inflammatory, and oxidative stress parameters, utilized as biomarkers of chronic and degenerative diseases. Although many natural products fermented with lactic acid bacteria (LAB) have shown beneficial effects on the immune system and on antioxidant defenses, formulations of papaya fermented with LAB have not yet been studied.
\end{abstract}

Aims: The aims of this study were to investigate the immunomodulatory activity linked to the type of papaya fermentation (yeast $v s$ LAB) in macrophages and to evaluate whether the type of 
fermentation differently modulates oxidative stress both in cell free system and in a model of embryonic brain cells.

Methods: Cytotoxicity was evaluated through cell proliferation kinetic and lactate dehydrogenase release assays; immunomodulatory activity through the transcriptional activation of inducible nitric oxide synthase (iNOS) and Tumor Necrosis Factor $\alpha$ (TNF $\alpha$ ) by qRT-PCR in RAW 264.7 macrophages; antioxidant capacity was assessed, in cell free system and in pheochromocytoma cells embryonic brain cells, by measuring the intracellular ROS levels through a fluorescent dye.

Results: Our data showed that all the formulations studied are safe at low concentrations (3-6 $\mathrm{mg} / \mathrm{ml}$ ); the LAB- fermented formulations promoted the expression of iNOS and TNF $\alpha$ more efficiently than yeast-fermented papaya preparation $(p<0.001)$. In a cell free system, the LABfermented formulation acted as mild scavengers of ROS while, in cells, both formulations didn't show any significant effect.

Conclusion: This study corroborates previous reports showing the efficacy of yeast fermented papaya as a potent immunostimulant and highlights the beneficial contribution of lactic bacteria fermentation.

Keywords: papaya, lactic fermentation, immunostimulant activity, antioxidant activity

\section{INTRODUCTION}

Dietary supplementation containing live bacteria promotes health effects and reduces the risk of various diseases [1] not only by affecting the intestinal microflora but also by modulating the immunological parameters and the intestinal permeability as well as by producing bioactive metabolites [2]. Lactic Acid Bacteria (LAB) are gram-positive, non-spore forming, anaerobic bacteria present in a variety of habitats including the human and animal intestinal tract, material of plant origin, and sewage; LAB are frequently used as probiotics, either alone or in combination of different strains for the fermentation of food products [3].

By considering the many types of potential fermentation substrates and conditions, LAB strains may be considered as functional performance bacteria and are expected to be used in the development of new food-based probiotics in the future. Even if many LAB are currently used in the dairy industry to produce cheese, yogurt, and other fermented milk products [4], increased use has been observed among the non-dairy probiotic foods, such as vegetables and fruit juices due to the high amounts of bioactive molecules produced by the proteolytic activity of LAB [5]. Lactic acid fermentation enhances the micronutrient profile of foods: fermented dairy products consistently reveal an increased level of folic acid which is critical for babies' health as well as pyroxidine, B vitamins, riboflavin, and biotin depending on the strains of bacteria present [6]. Vegetables, fruits, legumes, and grains subjected to lactic acid fermentation have an improved macro and micronutrient profiles and bioavailability, and are specifically characterized by increased levels of vitamin C, vitamin A, and lysine with its antiviral effects and methionine [7]. 
As probiotics, LAB are important for enhancing the immunity responses, the maintenance of the intestinal microbial balance and the prevention of gastrointestinal infection by influencing the biochemical, physiological, and antimicrobial activities or by changing the composition of the intestinal microflora [8]. Numerous cell types are involved in these responses, including epithelial cells, dendritic cells (DC), monocytes/macrophages, B cells, T cells, and NK cells [9]. Several strains of LAB (mostly Lactobacillus, Streptococcus, and Bifidobacterium strains) enhance both the innate and adaptive immune response through induction of dendritic cell maturation and further stimulating the lymphocytes to release pro-inflammatory cytokines, including tumor necrosis factor alpha (TNF $\alpha$ ), interferon-gamma (IFN $\gamma$ ), several interleukins (IL-1 $\beta,-6,-12$ ), and nitric oxide (NO) $[10,11]$. LAB fermentation is largely used not only to enhance the immune-modulatory features of several foods and botanicals [12], but also to increase the antioxidant features thanks to the degradation of polyphenols in the more bioavailable phenolic acids [13].

The balance between the production of ROS and antioxidants is essential in a biological system to prevent adverse effects of oxidative stress [14]. Antioxidant agents are able to modulate the concentration of ROS and RNS at a cellular level may, and are therefore helpful in preventing Alzheimer disease (AD) and several other diseases, especially ones related to aging such as diabetes, cancer, cardiovascular and neurological diseases, and cataracts and glaucoma [15-16]. Marchetti and Abbracchio in 2005 postulated that "novel therapeutic approaches must rely on potentiation of endogenous anti-inflammatory pathways and on a combination of treatment involving immune modulation and anti-inflammatory therapies" [17].

Fermented papaya preparation, produced by fermentation of Carica papaya Linn by using yeasts, is a well-known food supplement that exhibits anti-inflammatory, antioxidant, and immunostimulatory action, properties that may be helpful against age-related diseases [10, 16].

Since it has been shown that fermented foods with LAB can be beneficial to the immune system [18] and ameliorate the antioxidant activity [19] but formulations of papaya fermented with probiotics have not yet been studied, the purposes of this study were the following: 1) to compare the immunomodulatory activity linked to the type of papaya fermentation (yeast $v s$ LAB) through the analysis of the effects on the transcriptional activation of iNOS and TNF $\alpha$ in macrophages previously treated with IFN- $\gamma$, a well-known inducer of the initial steps of immune response and 2) to evaluate whether the type of papaya fermentation differently modulates oxidative stress both in cell free system and in a model of embryonic brain cells.

\section{MATERIALS AND METHODS}

\section{Materials}

The papaya fermented formulation used in this study is constituted by a puree of Papaya (Carica Papaya Linn) fermented through a process of lactic fermentation using a combination of three lactic acid bacteria strains (Streptococcus Thermophilus, Lactobacillus Acidophilus, Bifidobacterium A. Subsp. Lactis), named FPPB. Data where compared with a commercially available formulation of yeasts-fermented papaya (FPPA), known as Immunage, prepared at the Osato Research Institute, Gifu, Japan.

RAW264.7 and DMEM were obtained from the American Tissue Colture Collection. Fetal Bovine Serum (FBS), RPMI, horse serum, Penicillin/Streptomycin (P/S) solution, glutamine, 
Carboxy- $\mathrm{H}_{2}$ DCFDA, SuperScript III reverse transcriptase, random hexamers, dNTPs, RNase Out, mouse-IFN $\gamma$, and LDH cytotoxicity assay kit were purchased from Thermo Fischer (Carlsbad, CA, USA). RNeasy Mini Kit and Qiashredder were obtained from Qiagen (Hilden, Germany). PerfeCta SYBR Green SuperMix with ROX kit were from Quanta Biosciences (Gaithersburg, MD, US). Primers for RT-PCR were purchased from IDT (Coralville, IA, USA). PC12 cells, PBS tabs, collagen type IV, Trypsin-EDTA, Horseradish Peroxidase (HRP), Trolox (6-Hydroxy-2,5,7,8-tetramethylchromane-2-carboxylic acid), phenethyl isothiocyanate (PEITC), benzyl isothiocyanate (BITC), 2,2'-Azobis(2-methylpropionamidine), dihydrochloride (AAPH), and fluorescein sodium salt were purchased from Sigma Aldrich. ECL Western Lightning ULTRA Reagents was purchased from Perkin Elmer. All the other chemicals and solvents were of the highest analytical grade. All solutions were prepared with pyrogen-free reagent-grade water using a Milli-Q system (Millipore, Milan, Italy).

\section{Methods}

\section{Cell culture}

RAW 264.7 (mouse leukemic monocyte macrophage cell line) were grown in DMEM containing $10 \%$ FBS and P / S; for experiments we used the cells from passage 3 to 7 , in order to avoid possible changes of cellular phenotype. RAW 264.7 cells were incubated with solutions of FPP (3-6-9 mg / ml) in the presence or absence of IFN $\gamma 100 \mathrm{U} / \mathrm{ml}$ for 24 hours.

Rat adrenal pheochromocytoma PC12 cells were plated in collagen type IV coated flasks and grown in RPMI containing $10 \%$ horse serum, 5\% FBS, 2mM Glutamine, and P/S. Cells were incubated with solutions of FPP (3 and $6 \mathrm{mg} / \mathrm{ml}$ ) in a complete medium for 24 hours and the intracellular ROS levels were detected with the oxidant probe $\mathrm{H}_{2}$ DCFDA in the presence or absence of a 30 minutes exposure to $100 \mu \mathrm{M}$ hydrogen peroxide $\left(\mathrm{H}_{2} \mathrm{O}_{2}\right)$, as described in [20]. Trolox treatment was used as positive control (500 $\mu \mathrm{M}$ for 24 hours).

\section{Cell proliferation assay.}

$2.5 \times 10^{5}$ cells in the logarithmic growth phase were harvested and seeded in 24 wells overnight. The treatments were added and the cells were further incubated for various periods of time (2-47 days). At the end of incubation, cell number and viability was determined with Countess automated cell counter (Thermo Fischer) utilizing Trypan Blue as a dye. Growth kinetic curve was drawn according to the number of viable cells $v$ incubation time.

\section{RNA extraction.}

RAW $264.7\left(5.0 \times 10^{5} /\right.$ well) were incubated with solutions of FPP $(3 \mathrm{mg} / \mathrm{ml})$ in the presence or absence of IFN- $\gamma 100 \mathrm{U} / \mathrm{ml}$ for 24 hours. Total RNA was extracted using a commercially available kit (RNeasy Mini-Kit, Qiagen, Hilden, Germany) as it is reported in [21].

\section{Real-Time PCR.}

$500 \mathrm{ng}$ of total RNA were reverse transcribed in a volume of $25 \mu \mathrm{l}$ using 250 units of SuperScript III reverse transcriptase and $50 \mathrm{ng}$ of random hexamers as it is reported in Caliceti [21]. Reaction conditions were as suggested by the manufacturer. $2 \mu$ of the cDNA mixture were used for Real-Time PCR experiments to measure the amount of iNOS and TNF $\alpha$ transcripts (ref 
Caliceti plus one 2013). Real-Time PCR reactions were conducted on an Applied Biosystems 7500 Fast Real-Time PCR System using PerfeCta SYBR Green SuperMix with ROX kit (Quanta Biosciences) according to the manufacturer's protocol in a final volume of $25 \mu$. Primers concentration was $500 \mathrm{nM}$. The following primers were used: iNOS: forward 5' AGTCAACTGCAAGAGAACGGA-3', reverse 5'-GAAGAGAAACTTCCAGGGGCA-3', TNFa: forward 5'-ACTGAACTTCGGGGTGATCG-3', reverse 5'CCACTTGGTGGTTTGTGAGTG-3'. RPL13A forward 5'-AGCCCAGGGTGCTTTGCGG-3', reverse 5' GCGCCATGGCTGCCTCCTATAC-3'. Changes in gene expression were calculated by the $2^{-\Delta \Delta \mathrm{Ct}}$ formula using RPL13A as reference gene [21].

\section{Determination of oxygen radical scavenging capacity (ORAC)}

The antioxidant activity of the formulations was estimated by oxygen radical absorbance capacity (ORAC) assay, using fluorescein as the fluorescent probe [22]. Briefly, $50 \mu \mathrm{L}$ of blank, Trolox standard solutions $(10-50 \mu \mathrm{M})$, and several dilutions of the preparations (FPPA and FPPB: range from $9 \mathrm{mg} / \mathrm{ml}$ to $500 \mu \mathrm{g} / \mathrm{ml}$ ) were transferred to triplicate wells in a black 96-wells plate. After incubation at $37^{\circ} \mathrm{C}$ for $10 \mathrm{~min}, 50 \mu \mathrm{L}$ of fluorescein $(78 \mathrm{nM})$ was added to each well and cells were incubated at $37{ }^{\circ} \mathrm{C}$ for another $20 \mathrm{~min}$. Fluorescein consumption was immediately measured after adding $25 \mu \mathrm{L}$ of 2,2'-Azobis(2-methylpropionamidine) dihydrochloride (AAPH) (221 $\mathrm{mM}$ ) to each well at every $5 \mathrm{~min}$ for one hour on a Varioskan Flash reader (Thermo, USA) with the excitation at $485 \mathrm{~nm}$ and the emission at $535 \mathrm{~nm}$. Final values were calculated using the linear relationship $(\mathrm{Y}=\mathrm{a}+\mathrm{bX})$ between Trolox concentration $(\mathrm{X})(\mu \mathrm{M})$ and the area under the fluorescence versus time curve for samples minus the area under the curve for the blank (Y). ORAC values were expressed as micro mole Trolox equivalent per grams of sample $(\mu \mathrm{mol}$ Trolox equiv./g target compound). Data were presented as mean \pm SEM of three independent experiments.

\section{Intracellular ROS measurement}

Intracellular levels of ROS were measured as previously described [20]. Briefly, PC12 cells $\left(8 \times 10^{4} / \mathrm{ml}\right)$ were seeded in a black 96 wells plate and treated with solutions of FPP, FPPA and FPPB at a concentration of 3 and $6 \mathrm{mg} / \mathrm{ml}$ for 24 hours. Cells were washed in PBS and incubated with $5 \mu \mathrm{M} \mathrm{2}, 7^{\prime}$-dichlorofluorescin-diacetate $\left(\mathrm{DCFH}_{2}-\mathrm{DA}\right)$ for $20 \mathrm{~min}$ at $37^{\circ} \mathrm{C}$. The fluorescence of oxidized probes was measured on a multiwell plate reader (Varioskan, Thermo Scientific) in the presence or absence of 30 min treatment with $100 \mu \mathrm{M}$ of hydrogen peroxide $\left(\mathrm{H}_{2} \mathrm{O}_{2}\right)$. Trolox treatment $(500 \mu \mathrm{M}$ for 24 hours) was used as positive control. Excitation wavelength was $485 \mathrm{~nm}$ and emission wavelength was $535 \mathrm{~nm}$.

\section{Statistical analysis}

Results are expressed as means of three independent experiments with SEM. The statistical probability was determined by two-tailed Student's t test and considered to be significantly different at the level of $\mathrm{p}<0.05$. 


\section{RESULTS AND DISCUSSION}

\section{Safety of FPP formulations using an in vitro assay.}

When used for the treatment of RAW 264.7 and PC12 cell lines at different concentrations ranging from 3 to $9 \mathrm{mg} / \mathrm{ml}$ for 2 and 4 days (Figures 1 and 2) all the formulations didn't reduce the cell proliferation, as demonstrated by the growth curves and the number of dead cells, which was less than $15 \%$, similar to control group using only the vehicle (Figures 1 and 2).

At day 7, cells treated with (both RAW 264.7 and PC12) formulations at concentration 9.0 $\mathrm{mg} / \mathrm{ml}$ were almost all dead while those treated with the formulations at lower concentrations ( 3 and $6 \mathrm{mg} / \mathrm{ml}$ ) were in over-confluence (data not shown).

A

FPPA

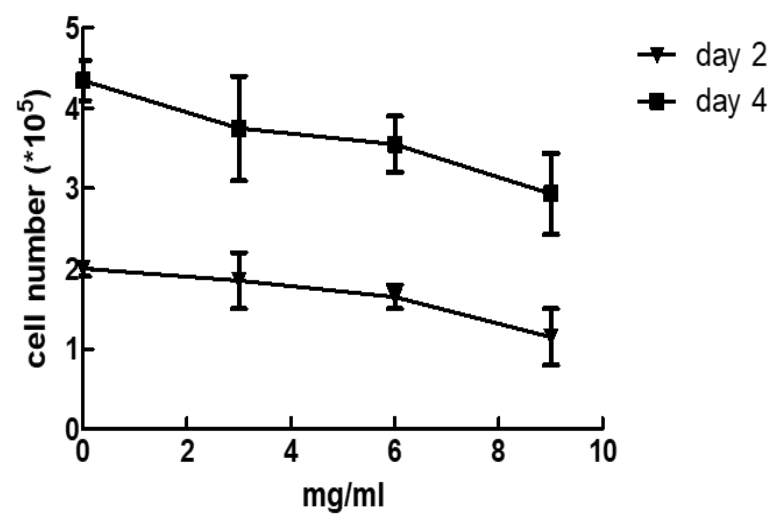

B

FPPB

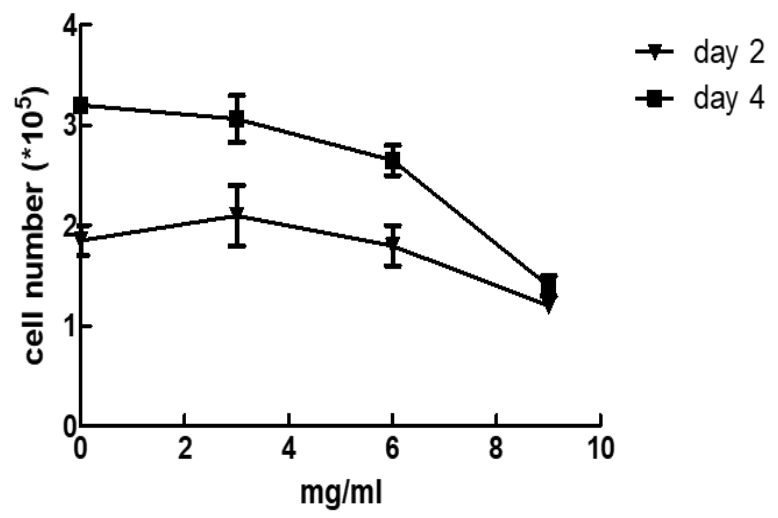

Figure 1. Curve of growth of rat macrophages (RAW264.7 cells). Proliferation of RAW264.7 cells was determined in relation to growth curve, based on the measurement of cell number at each time point. $2,5 \times 10^{5}$ cells in the logarithmic growth phase were incubated with (A) FPPA at 3, 6, $9 \mathrm{mg} / \mathrm{ml}$ for 2, 4 and 7 days and (B) FPPB at 3,6, $9 \mathrm{mg} / \mathrm{ml}$ for 2, 4, and 7 days. At each time point, cells were harvested and counted using an automated cell counter. Data are mean value of three independent experiments.

A

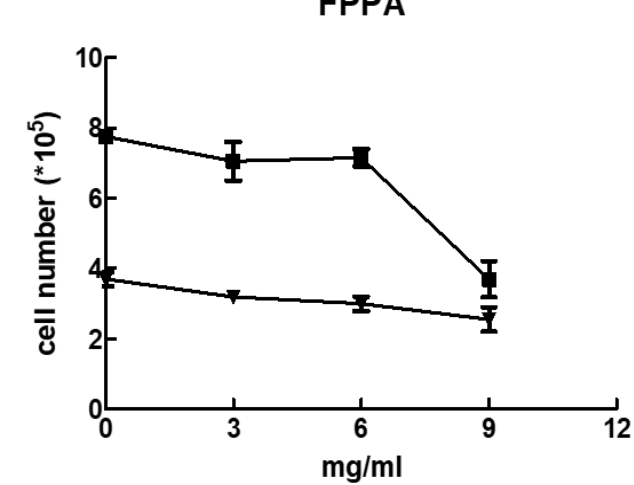

B

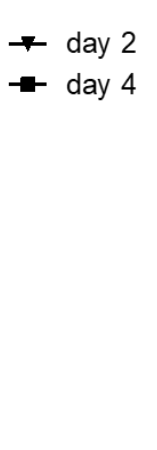

FPPB

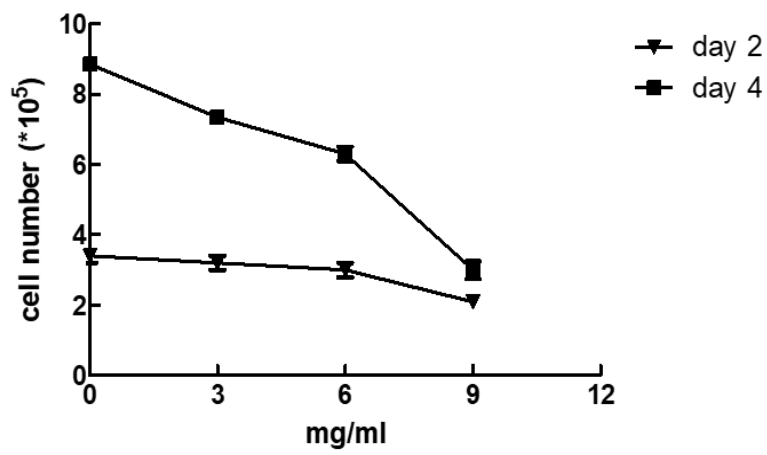

Figure 2. Curve of growth of rat neuronal cells (PC12 cells). Proliferation of PC12 cells was determined in relation to growth curve, based on the measurement of cell number at each time point. $2,5 \times 10^{5}$ cells in the logarithmic growth phase were incubated with (A) FPPA at 3,6,9 mg/ml for 2, 4 and 7 days and (B) FPPB at 3,6,9 mg/ml for 2, 4 and 7 days. At each time point cells were harvested and counted using an automated cell counter. Data are mean value of three independent experiments. 
Effect of FPP formulations on iNOS and TNFa mRNA expression in IFNy-stimulated macrophages.

To compare the immunomodulatory activity of the different formulations, the expression of iNOS and TNF $\alpha$ was evaluated through quantitative Real-Time PCR, in mouse RAW264.7 macrophage cells previously stimulated with IFN $\gamma$. In order to set the experimental conditions, RAW 264.7 were first treated with different concentrations of IFN $\gamma$ at different time points (10 and $100 \mathrm{U} / \mathrm{ml}$ for 4 and 24 hours), in order to set the experimental conditions. The results showed that treatment of IFN $\gamma 100 \mathrm{U} / \mathrm{ml}$ for 24 hours promotes a significant increase in the expression of iNOS and TNF $\alpha$ ( $\mathrm{p}<0.001$ ) (Figure 3 A and B). Next, RAW 264.7 cells were incubated with FPP formulations at a concentration of $3 \mathrm{mg} / \mathrm{ml}$ for 24 hours, in the presence or absence of IFN $\gamma(100 \mathrm{U} / \mathrm{ml})$. In the presence of IFN $\gamma$, FPPA induced a higher iNOS expression compared to IFN $\gamma$ treatment alone, as previously reported by Rimbach et al. [23]. In the presence of IFN $\gamma$, FPPB treatment exhibited a significantly increase of iNOS expression compared to FPPA ( $\mathrm{p}<0.001$ ) (Figure 3C). The expression of TNF $\alpha$ increased in the presence of FPPB ( $p$ $<0.005$ ) (Figure 3D) while there wasn't any statistically difference in the presence of FPPA but a tendency to increase. Kobuchi et al. showed that TNF $\alpha$ and IL-1 $\beta$ are involved in the induction of iNOS gene and Bio Normalizer (a natural health food supplement prepared from yeastfermented Carica papaya and some other medicinal plants) increased the mRNA expression of both these cytokines in the presence of IFN $\gamma$ [24]. Rimbach et al., investigating the secretion of $\mathrm{TNF} \alpha$ in the cellular medium, observed a significant increase in $\mathrm{TNF} \alpha$ as a result of treatment with yeast-fermented papaya. The discrepancy on the induction of TNF $\alpha$ by FPPA between our and these two studies is probably due to the difference in the experimental procedures. Several studies assessed the effect of FPPA on nitric oxide production and TNF $\alpha$ secretion in RAW 264.7 macrophages indicating that it exerts immunomodulatory activity [23]. NO, as a freeradical gasomediator, is synthesized by inducible nitric oxide synthase (iNOS) and mediates diverse functions, including immunoresponses, inhibition of platelet aggregation and of extracellular matrix production [25] to destroy invading pathogenic microbes as part of the body's defense mechanism against disease [26].

FPPA was found to up-regulate the IFN $\gamma$-induced NO production in a dose-dependent manner [24]. The effect of FPPA on NO production was not due to changes in the activity of iNOS but to the increase of iNOS mRNA. Interestingly, the ability of FPPA to augment IFN $\gamma$ induced iNOS mRNA expression was independent of any changes on the mRNA stability [24]. FPPA alone did not affect NO production but also augmented the mRNA expression of TNF $\alpha$ and interleukin-1 $\beta$ in the presence of IFN $\gamma$, which in turn determines the induction of iNOS gene, thereby suggesting that FPPA may not only be directly involved in the expression of iNOS but also has potential synergistic interaction with IFN $\gamma$ to induce NO synthesis [24]. 
A

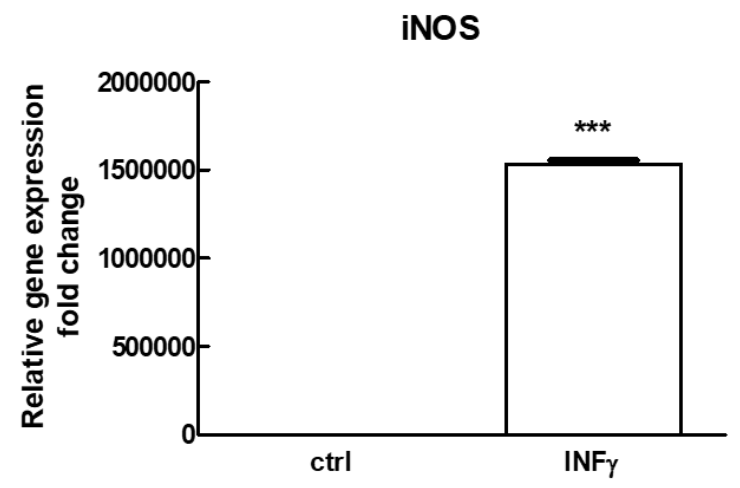

C

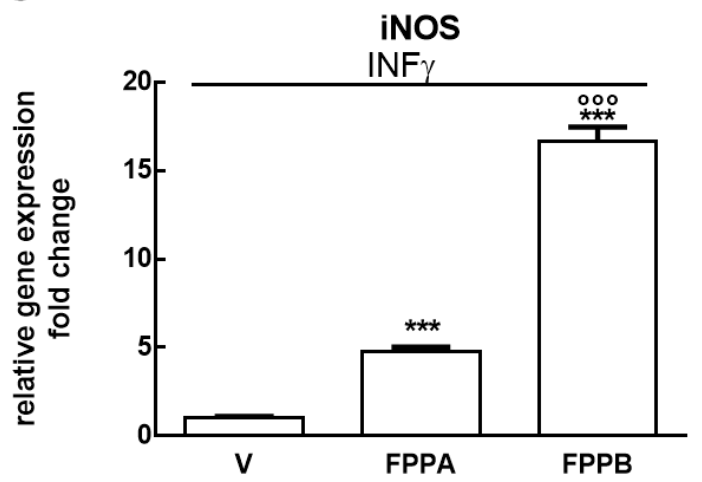

B

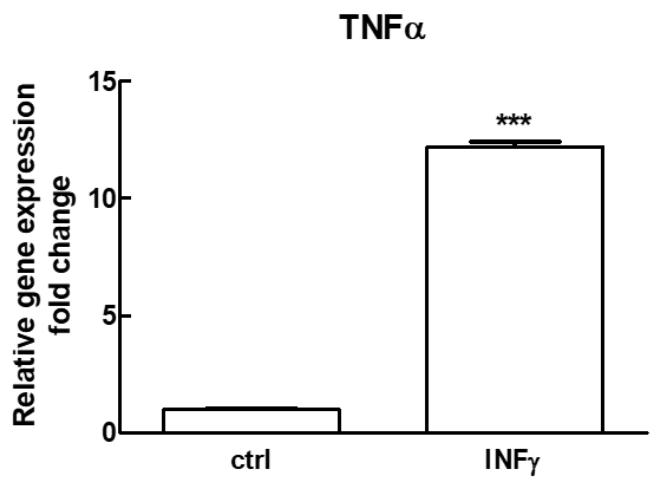

D

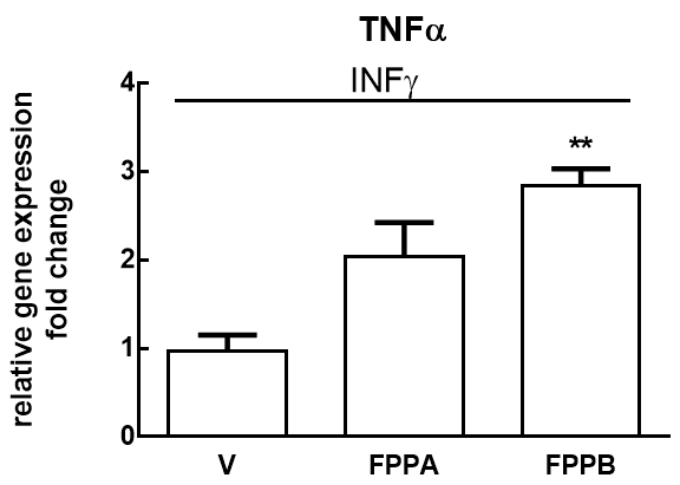

Figure 3. Immunostimulant activity of FPP formulations in rat macrophages. RAW 264.7 were treated with $100 \mathrm{U} / \mathrm{ml}$ of Interferon $\gamma$ (IFN $\gamma$ ) for 24 hours. Total RNA was extracted and qRT-PCR analysis of (A) iNOS and (B) TNF $\alpha$ gene expression was performed. RAW 264.7 were treated with $100 \mathrm{U}$ $/ \mathrm{ml}$ of Interferon $\gamma$ (IFN $\gamma$ ) for 24 hours in the presence of FPPA $(3 \mathrm{mg} / \mathrm{ml})$ and FPPB $(3 \mathrm{mg} / \mathrm{ml})$. Total RNA was extracted and qRT-PCR analysis of (C) iNOS and (D) TNF $\alpha$ gene expression was performed. Relative changes in mRNA expression levels were calculated according to the 2- $\Delta \Delta \mathrm{Ct}$ method using RPL13A as reference gene. Results are expressed as mean \pm SEM of three independent experiments. ** $\mathrm{P}<0.01, * * * \mathrm{P}<0.001$ significantly different from the control; ${ }^{\circ} \mathrm{P}<0.001$ significantly different from FPPA.

ROS scavenging activity and antioxidant effect of FPP formulations in PC12 cells.

Earlier studies have indicated that FPPA has antioxidant activity in vitro and in vivo via inhibition of lipid peroxidation and protection of human $\mathrm{T}$-lymphocytes challenged with ferric nitrilotriacetate and hydrogen peroxide $\left(\mathrm{Fe}-\mathrm{NTA} / \mathrm{H}_{2} \mathrm{O}_{2}\right)$ that induce single and double strand breaks [27].

Electron paramagnetic resonance (EPR) spin trapping studies demonstrated that antioxidant properties of FPPA are related to both hydroxyl scavenging as well as iron chelating properties [27-28]. It has been discovered that FPPA scavenges superoxide anion radicals generated by the hypoxanthine-xanthine oxidase system [27].

In the present study, preliminarily the direct "scavenger activity" of the preparations was determined through $\mathrm{ORAC}_{\mathrm{FL}}$ assay, and intracellular ROS measurements were performed on pheochromocytoma PC12 cells exposed to an oxidative stress.

Data in Table 1 revealed that FPPB acts as a mild scavenger of ROS while having higher activity in comparison to FPPA which revealed a low effect (Table 1). This was probably due to LAB fermentation which has been discovered to enhance the overall functional properties of 
foods beyond original nutritional values, primarily due to the biotransformation of phenolics [29]. In contrast with Amer et al. [30], our data revealed a clear scavenging effect of FPPA in a cell-free system measured by one unconventional method, specifically by using dichloro-dihydro fluorescein (DCF) as a probe.

The in vitro antioxidant activity of the formulations was then evaluated in rat pheochromocytoma PC12 cells, a mixture of neuroblastic and eosinophilic cells able to differentiate into neurons [31], which was used as a model of brain, the organ most affected by hypoxia and consequent oxidative stress. In the presence of $100 \mu \mathrm{M}$ of $\mathrm{H}_{2} \mathrm{O}_{2}$ for $30 \mathrm{~min}$, mimicking intracellular oxidative stress, the formulations FPPA and FPPB at 3 and $6 \mathrm{mg} / \mathrm{ml} \mathrm{did}$ not significantly affect ROS level (Figure 4) in PC12 cells, even if there is a tendency to decrease. Aruoma et al. showed that FPPA treatment prior to incubation with $\mathrm{H}_{2} \mathrm{O}_{2}$ protects from oxidative DNA damage PC12 cells, significantly increasing viability and sustaining morphology and shape of cells, at least in part through the reduction of the MAPK p38 phosphorylation [32]. Similarly, Zhang et al. (2006) found that supplementation of FPPA in an Alzheimer's disease cell model represented by SH-SY5Y cells (APP cells) stably overexpressing a $\beta$-amyloid precursor protein Swedish mutated (APPsw) was able to decrease the production of hydroxyl radicals and superoxide anion [33]. Thus, our results may be due to the different cellular model and/or the different method utilized to assess the antioxidant activity. In a nutrigenomics study related to FPPA efficacy, Marotta et al. [34] found that the genes for antioxidant enzymes catalase, superoxide dismutase (SOD), and glutathione peroxidase, as well as the gene for the DNA repair enzyme human 8-oxoguanine glycosylase (hOGG1), were up-regulated by FPPA. As a result, further studies (either in animals or in humans) are needed to corroborate our preliminary data of the beneficial effects of the LAB-fermented preparations in oxidative stress.

Table 1. ORAC $\mathrm{FL}_{\mathrm{F}}$ assay

\begin{tabular}{|c|l|}
\hline & ORAC $F L(\mu$ mol Trolox equiv./g sample $)$ \\
\hline FPPA & $5 \pm 1$ \\
\hline FPPB & $24 \pm 2$ \\
\hline
\end{tabular}

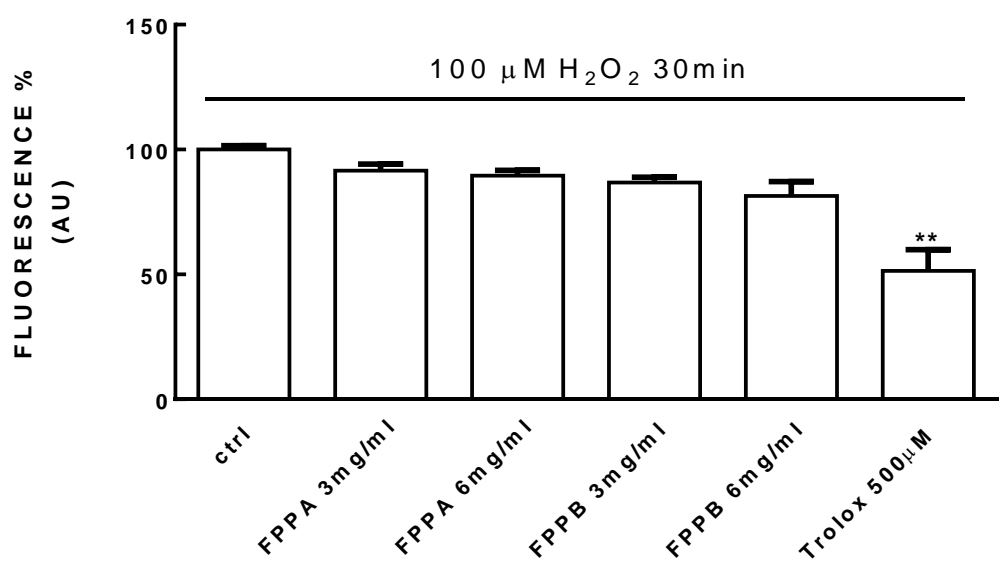

Figure 4. Antioxidant activity of FPP formulations in PC12 cells. PC12 cells were treated for $24 \mathrm{~h}$ with FPPA $(3,6 \mathrm{mg} / \mathrm{ml})$, FPPB $(3,6 \mathrm{mg} / \mathrm{ml})$ or Trolox $(500 \mu \mathrm{M})$ and then exposed to oxidative stress generated by $100 \mu \mathrm{M} \mathrm{H} 2 \mathrm{O} 2$ for $30 \mathrm{~min}$. ROS levels were measured by means of H2DCF-DA assay as described in Materials and Methods Section. Results are expressed as means \pm SEM of three independent experiments. $* * \mathrm{P}<0.01$ significantly different from the control $(\mathrm{V})$. 


\section{CONCLUSION}

The European vision of the Joint Programming Initiative (JPI) "A healthy diet for a healthy life" is that by 2030 all citizens will have the motivation, ability, and opportunity to consume a healthy diet from a variety of foods (included functional foods and supplements), to have healthy levels of physical activity, and significant decrease of diet-related diseases. In this context, new findings reported in this study indicate that a Carica papaya preparation fermented with LAB can improve the immune function as well as the antioxidant defenses. This report supports the context that a supplementation of nutraceuticals and/or functional food exhibiting antioxidant and immunostimulatory effects may have beneficial prophylactic properties in the management of chronic diseases linked to aging and expands their uses as a multifunctional agent in preventive medicine.

This study was conducted in vitro, and further in vivo studies are needed to confirm these findings in animals and humans. The chemical structure and effective dosage of functional candidate compounds are different in vivo from that in vitro. Recently it has been demonstrated that yeast fermented papaya preparation contains single phenolic acids and many kinds of lowmolecular-weight substances but no polymerized structures [35]. These low-molecular-weight substances behave similar to polymerized polyphenols in vivo that are broken down and absorbed in the intestines by intestinal microflora, suggesting that the original structures of polyphenols do not necessarily mediate their functions in vivo.

In a recent paper by Yuhzo Fujita et al. [35], clinical effects of yeast fermented papaya administration ( 3 and $9 \mathrm{~g}$ /day) in tube-fed older patients were observed, demonstrating that lowmolecular-weight phenolic acids are bioactive. This study is in accordance with several studies that have demonstrated that aerobic fermentation enhances polyphenol bioactivity [36-38]. Yuhzo Fujita et al. also showed that yeast-fermented papaya supplementation affected the composition of colon microflora, reducing the abundance of Firmicutes possibly through the decrease of bile acids. Consequently, development of fermentation biotechnology may introduce useful low-molecular-weight compounds with improved absorption and human health benefits.

In order to explain the increase of the immunostimulant and antioxidant activities due to lactic acid fermentation, a metabolomic study will be conducted to characterize the metabolites in Carica papaya preparation after LAB fermentation.

List of Abbreviations: FPPA, commercially yeast-fermented papaya preparation; FPPB, lacticfermented papaya preparation; LAB, lactic acid bacteria; DCF, dichloro-dihydro fluorescein; $\mathrm{TNF} \alpha$, tumor necrosis factor alpha; IFN $\gamma$, interferon-gamma

Competing Interests: The authors declare that they have no conflict of interests.

Authors' Contributions: $\mathrm{CC}$ and $\mathrm{PR}$ designed the research. $\mathrm{MR}$ and FG provided the formulations. CC, FF, GA, DC, EP, LU, MM and PS conducted the research. CC, DC, MG and PR performed statistical analyses. CC wrote the manuscript. RF and AR had primary responsibility for the final content. All authors read and approved the final version of the manuscript.

Acknowledgments and Funding: This study was funded by INCOS Cosmeceutica Industriale, Funo di Argelato, Bologna, Italy. 


\section{REFERENCES:}

1. Ahrne S, Nobaek S, Jeppsson B, Adlerberth I, Wold AE, Molin G: The normal Lactobacillus flora of healthy human rectal and oral mucosa. J Appl Microbiol 1998; 85(1):88-94.

2. De VM, Schrezenmeir J: Probiotics, prebiotics, and synbiotics. Adv Biochem Eng Biotechnol 2008; 111:1-66.

3. Chiang SS, Pan TM: Beneficial effects of Lactobacillus paracasei subsp. paracasei NTU 101 and its fermented products. Appl Microbiol Biotechnol 2012; 93(3):903-916.

4. Schmid K, Schlothauer RC, Friedrich U, Staudt C, Apajalahti J, Hansen EB: Development of probiotic food ingredients. In Probiotics in food safety and human health. Edited by Goktepe et al. Boca Raton, FL: CRC (Taylor \& Francis Group); 2006: 35-66.

5. Pessione E, Cirrincione S: Bioactive Molecules Released in Food by Lactic Acid Bacteria: Encrypted Peptides and Biogenic Amines. Front Microb Front Microbiol 2016; 7:876.

6. Kneifel W, Mayer HK: Vitamin Profiles of Kefir Made from Milk of Different Species. Int J of Food Science \& Tech 1991, 26,423-428.

7. Odunfa SA, Adenirana SA, Teniolaa OD, Nordstromb J: Evaluation of lysine and methionine production in some Lactobacilli and yeasts. Int $\mathbf{J}$ of Food Microbiol 2001, 63(1-2): 159-163.

8. Perdigon G, Fuller R, Raya R: Lactic acid bacteria and their effect on the immune system. Curr Issues Intest Microbiol 2001, 2(1):27-42.

9. Ng SC, Hart AL, Kamm MA, Stagg AJ, Knight SC: Mechanisms of action of probiotics: recent advances. Inflamm Bowel Dis 2009, 15:300-310.

10. Aruoma OI, Hayashi Y, Marotta F, Mantello P, Rachmilewitz E, Montagnier L: Applications and bioefficacy of the functional food supplement fermented papaya preparation. Toxicology 2010, 278: 6-16.

11. Perdigon G, Vintini E, Alvarez S, Medina M, Medici M: Study of the possible mechanisms involved in the mucosal immune system activation by lactic acid bacteria. J Dairy Sci 1999, 82:1108-1114.

12. Rizzello CG, Coda R, Sanchez-Macías D, Pinto D, Marzani B, Filanino P, Giuliani G, et al.: Lactic acid fermentation as a tool to enhance the functional features of Echinacea spp. Microb Cell Fact 2013, 12:44

13. Curiel JA, Pinto D, Marzani B, Filannino P, Farris GA, Gobbetti M, Rizzello CG: Lactic acid fermentation as a tool to enhance the antioxidant properties of Myrtus communis berries. Microb Cell Fact 2015, 14:67.

14. Houstis N, Rosen ED, Lander ES: Reactive oxygen species have a causal role in multiple forms of insulin resistance. Nature 2006, 440(7086):944-8.

15. Uttara B, Singh AV, Zamboni P, Mahajan RT: Oxidative stress and neurodegenerative diseases: a review of upstream and downstream antioxidant therapeutic options. Curr Neuropharmacol, 2009, 7(1):65-74. 
16. Barbagallo M, Marotta F, Dominguez LJ: Oxidative stress in patients with Alzheimer's disease: effect of extracts of fermented papaya powder. Mediators Inflamm 2015:624801.

17. Marchetti B, Abbracchio MP: To be or not to be (inflamed)--is that the question in antiinflammatory drug therapy of neurodegenerative disorders? Trends Pharmacol Sci 2005, 26(10):517-25.

18. Zagato E, Mileti E, Massimiliano L, Fasano F, Budelli A, Penna G, et al.: Lactobacillus paracasei CBA L74 metabolic products and fermented milk for infant formula have antiinflammatory activity on dendritic cells in vitro and protective effects against colitis and an enteric pathogen in vivo. PLoS One 2014, 9:e87615.

19. Takeda S, Matsufuji H, Nakade K, Takenoyama SI, Ahhmed A, Sakata R, Kawahara S, et al.: Investigation of lactic acid bacterial strains for meat fermentation and the product's antioxidant and angiotensin-I-converting-enzyme inhibitory activities. Anim Sci J 2017, 88(3):507-516.

20. Zambonin L, Caliceti C, Vieceli Dalla Sega F, Fiorentini D, Hrelia S, Landi, Prata C: Dietary Phenolic Acids Act as Effective Antioxidants in Membrane Models and in Cultured Cells, Exhibiting Proapoptotic Effects in Leukaemia Cells. Ox Med and Cell Long 2012, 83:92-98.

21. Caliceti C, Aquila G, Pannella M, Morelli MB, Fortini C, Pinton P, Bonora M, et al.: 17bEstradiol Enhances Signalling Mediated by VEGF-A-Delta-Like Ligand 4-Notch1 Axis in Human Endothelial Cells. PLoS One 2013, 8 (8):e71440.

22. Cao G, Alessio HM, Cutler RG: Oxygen-radical absorbance capacity assay for antioxidants. Free Radic Biol Med 1993, 14(3):303-311.

23. Rimbach G, Park YC, Guo Q, Moini H, Qureshi N, Saliou C, Takayama K, et al.: Nitric oxide synthesis and TNF-alpha secretion in RAW 264.7 macrophages: mode of action of a fermented papaya preparation. Life Sci 2000, 67:679-94.

24. Kobuchi H, Packer L: Bio-normalizer modulates interferon-gamma-induced nitric oxide production in the mouse macrophage cell line RAW 264.7. Biochem Mol Biol Int 1997, 43:141-52.

25. Olas B: Gasomediators (NO, CO, and $\mathrm{H} 2 \mathrm{~S}$ ) and their role in hemostasis and thrombosis. Clinica Chimica Acta 2015, 445: 115-121.

26. Young I, Woodside J: Antioxidants in health and disease. J Clin Pathol 2001, 54: 176-186.

27. Rimbach G, Guo DQ, Akiyama T, Matsugo S, Moini H, Virgili F, Packer L: Ferric nitrilotriacetate induced DNA and protein damage: inhibitory effect of a fermented papaya preparation, Anticancer Research 2000, 20: 2907-2914

28. Santiago LA, Osato JA, Hiramatsu M, Edamatsu R, Mori A: Free radical scavenging action of Bio-catalyzer alpha.rho No.11 (Bio-normalyzer) and its by-product. Free Radic Biol Med 1991, 11(4):379-83.

29. Bhattacharya S, Gachhui R, Sil PC: Effect of Kombucha, a fermented black tea in attenuating oxidative stress mediated tissue damage. Food Chem Toxicol 2013, 60, $328-34031.3$ 
30. Amer J, Goldfarb A, Rachmilewitz EA, Fibach E: Fermented papaya preparation as redox regulator in blood cells of beta-thalassemic mice and patients. Phytother Res 2008, 22:8208.

31. Greene LA, Tischler AS: Establishment of a noradrenergic clonal line of rat adrenal pheochromocytoma cells which respond to nerve growth factor. PNAS 1976, 73: 24242428.

32. Aruoma OI, Colognato, Fontana I, Gartlon J, Migliore L, Koike K, Coecke S, et al.: Molecular effects of fermented papaya preparation on oxidative damage, MAP Kinase activation and modulation of the benzo[a]pyrene mediated genotoxicity. BioFactors 2006, 26: 147-159.

33. Zhang J, Mori A, Chen Q, Zhao B: Fermented papaya preparation attenuates beta-amyloid precursor protein: beta-amyloid-mediated copper neurotoxicity in beta-amyloid precursor protein and beta-amyloid precursor protein Swedish mutation overexpressing SH-SY5Y cells. Neuroscience 2006, 143: 63-72.

34. Marotta F, Koike K, Lorenzetti A, Jain S, Signorelli P, Metugriachuk Y, Mantello P, Locorotondo N: Regulating redox balance gene expression in healthy individuals by nutraceuticals: a pilot study. Rejuvenat Res 2010; 13: 175-178.

35. Fujita Y, Tsuno H, Nakayama J: Fermented Papaya Preparation Restores Age-Related Reductions in Peripheral Blood Mononuclear Cell Cytolytic Activity in Tube-Fed Patients. PLoS On. 2017;12(1):e0169240.

36. Lin S, Yang B, Chen F, Jiang G, Li Q, Duan X, et al.: Enhanced DPPH radical scavenging activity and DNA protection effect of litchi pericarp extract by Aspergillus awamori bioconversion. Chem Cent J 2012, 6:108.

37. Lee HS, Kim MR, Park Y, Park HJ, Chang UJ, Kim SY, et al.: Fermenting red ginseng enhances its safety and efficacy as a novel skin care anti-aging ingredient: In vitro and animal study. J Med Food 2012, 15: 1015-1023.

38. Ryu JS, Lee HJ, Bae SH, Kim SY, Park Y, Suh HJ, et al.: The bioavailability of red ginseng extract fermented by Phellinus linteus. J Ginseng Res 2013, 37: 108-116. 